\title{
AKSI PENYERANGAN NON-PLAYER CHARACTER (NPC) MENGGUNAKAN METODE NAÏVE BAYES PADA SHOOTER GAME
}

\author{
Edi Siswanto*1, Alfa Faridh Suni \\ 1,2 Universitas Negeri Semarang, Semarang \\ Email: 1edi99@students.unnes.ac.id, ${ }^{2}$ alfafs@mail.unnes.ac.id \\ *Penulis Korespondensi
}

(Naskah masuk: 28 Juli 2020, diterima untuk diterbitkan: 16 November 2021)

\begin{abstract}
Abstrak
Aksi penyerangan pada non-player character (NPC) merupakan salah satu substansi penting dalam pembuatan game. Dalam melakukan penyerangan diperlukan strategi khusus agar NPC tidak mudah dikalahkan. Salah satunya adalah adanya variasi serangan terhadap pemain. Salah satu metode yang digunakan untuk mengatur penyerangan NPC adalah rulebase. Metode rulebase dapat memberikan variasi serangan sesuai kondisi NPC, namun metode rulebase bisanya menghasilkan behaviour yang statis dan tidak adaptif jika terdapat kondisi baru. AI seperti ini akan mudah diprediksi dan repetitif sehingga menurunkan tingkat tantangan bermain game. Untuk mengatasi masalah tersebut banyak peneliti yang menggunakan teknik learning. Salah satunya menggunakan metode nä̈ve bayes. Pada penelitian ini dilakukan penerapan metode naïve bayes sebagai strategi penyerangan NPC pada shooter game. Metode naïve bayes digunakan untuk keputusan serangan yang diambil oleh NPC. Adapun parameter yang digunakan untuk keputusan penyerangan adalah nyawa, jarak, jumlah granat, dan jumlah amunisi yang dimiliki NPC. Sedangkan keputusan penyerangan dibagi menjadi serangan tembak, serangan granat, dan serangan pisau. Hasil penelitian menunjukkan penerapan metode naïve bayes membuat NPC mampu melakukan penyerangan secara otonom jika terdapat kondisi baru dengan akurasi $80 \%$. Penerapan metode nä̈ve bayes juga lebih unggul dalam persentase kemenangan NPC dibanding metode rulebase. Tingkat kemenangan NPC menggunakan metode naïve bayes sebesar $60 \%$ sedangkan rulebase sebesar $16 \%$.
\end{abstract}

Kata kunci: Aksi Penyerangan, NPC, Nä̈ve Bayes, Rulebase

\section{ATTACKING BEHAVIOUR OF NON-PLAYER CHARACTER (NPC) USING NAÏVE BAYES METHOD IN SHOOTER GAME}

\begin{abstract}
Non-Player Character's (NPC) attacks behaviour is one important substance in making games. While NPC attacks needs specific strategy to not get defeated easily. One of the NPC attacks strategy is a variation of offense to player. One of the methods to manage the NPC attack strategy is rulebase. Rulebase method can give variations of the NPC attacks according in conditions, but rulebase method usually producing static behaviour and not adaptive where there is new condition. AI like this would easy too predictive and repetitive so that decrease the challenge of playing games. To overcome these problems, we use naïve bayes method. In this study, naïve bayes method are applied as an NPC's attack strategy to the shooter game. Naïve bayes method used for attack decisions taken by the NPC. The parameters used for the attack's decision are health point, distance, number of grenades, and number of ammunitions owned by the NPC. While attacks decision is divided into firing attacks, grenade attacks, and melee attacks. The results showed that the use naïve bayes method can attack autonomously if there are new condition with an accuracy of $80 \%$. The implementation of naïve bayes method at NPC more superior than rulebase method in percentage of NPC winning. The NPC win rate uses the naïve bayes method is $60 \%$ while the rulebase is $16 \%$.
\end{abstract}

Keywords: Attacking Behaviour, NPC, Nä̈ve Bayes, Rulebase

\section{PENDAHULUAN}

Salah satu produk teknologi komputer yang perkembangannya cukup pesat adalah game. Ada banyak genre game yang telah dikembangkan salah satunya shooter game. Dalam memainkan shooter game pemain diharuskan melakukan aksi cepat dalam merespon keadaan yang terjadi, sehingga memungkinkan pemain dapat melatih ketangkasan mereka (Frosi \& Cristina, 2018). Pengembangan 
shooter game tidak lepas dari agen NPC. NPC merupakan karakter dalam game yang tidak dapat dimainkan oleh pemain dan berperan sebagai musuh atau lawan (Liarokapis, Debattista, Vourvopoulos, Petridis, \& Ene, 2014). Agar NPC berperilaku cerdas dibutuhkan kecerdasan buatan dalam pembuatan game. Kecerdasan buatan atau Artificial Intelligence (AI) adalah model di dalam sistem yang belajar dari pengalaman dan mampu membuat keputusan dari inputan baru (Safrizal \& Setiawan, 2019). Pada kasus shooter game, perilaku menyerang merupakan substansi penting dalam pengembangan game untuk mewujudkan game menjadi realistis (Asmiatun, Hermawan, \& Daryatni, 2103). Model perilaku penyerangan NPC pada shooter game biasanya dimodelkan dengan finite state machine (FSM). FSM merupakan alur untuk menggambarkan perpindahan state perilaku NPC Seperti dari mengejar berubah menjadi menyerang karena mendapat kondisi tertentu.

Permasalahan yang muncul pada saat menyerang adalah bagaimana membuat NPC agar tidak mudah dikalahkan. NPC yang hanya dapat menyerang saja mudah dikalahkan oleh pemain. Beberapa inovasi telah dilakukan pada agen NPC dari segi behaviour sebagai solusi untuk menciptakan NPC yang lebih agresif. Salah satunya adalah memberikan variasi serangan pada agen NPC (Wicaksono, Hariadi, \& Mardi, 2013).

Salah satu metode yang digunakan untuk merancang variasi serangan NPC yaitu menggunakan rulebase (Yunanta, 2017). Penerapan rulebase menghasilkan sebuah kecerdasan buatan yang dapat membuat variasi penyerangan NPC sesuai kondisi yang telah ditentukan. Rulebase merupakan sistem yang berisi aturan-aturan yang disimpan dalam bentuk pengetahuan untuk dipelajari oleh AI (Roastiningsih, Gregorius, \& Wijaya, 2013). Namun metode rulebase bisanya menghasilkan behaviour yang statis dan tidak adaptif jika terdapat kondisi baru. AI seperti ini akan mudah diprediksi dan repetitif sehingga menurunkan tingkat tantangan bermain game (Wang \& Tang, 2015). Selain itu, terdapat pemelitian yang menunjukkan penerapan rulebase sebagai kecerdasan buatan memberikan tingkat kemenangan NPC sebesar 22\% sampai 25\% (Abdi, et al., 2017; Putera dan Herumurti, 2018). Berdasarkan hal tersebut banyak peneliti yang memanfaatkan teknik learning. Teknik learning tersebut diterapkan menggunakan algoritma klasifikasi seperti k-nearest neighbor (K-NN), decision tree, support vector machine (SVM), dan naïve bayes. Dari beberapa algoritma klasifikasi tersebut metode naïve bayes relatif lebih unngul (Ashari, Paryudi, \& Tjoa, 2013; Osisanwo, Akinsola, Awolede, \& Himnikaiye, 2017). Seperti penelitian Sanjaya, et, al. (2019) yang menerapkan metode naïve bayes sebagai AI pada racing game untuk keputusan pengereman (braking decision). Hasil penelitian menunjukkan bahwa metode naïve bayes mampu memberikan keputusan pengereman dengan baik tanpa menabrak dinding hasil dari pembelajaran data training. Metode naïve bayes memiliki kemampuan klasifikasi data dengan akurasi yang tinggi (Gata, et al., 2019). Selain itu metode nä̈ve bayes dapat dilatih dengan dataset kecil (Kaviani \& Dhotre, 2017). Asmiatun dan Hendrawan (2016) juga menerapkan metode naïve bayes untuk strategi menyerang NPC. Parameter yang digunakan pada penelitian tersebut adalah kekuatan serang, nyawa, dan jarak. Sedangkan klasifikasi perilaku penyerangan terdiri dari memukul dan menggigit. Pada penelitian tersebut NPC mampu melakukan penyerangan sesuai kondisi yang dialami. Namun pada penelitian tersebut strategi penyerangan hanya pada jarak dekat, sehingga NPC hanya dapat menyerang dari jarak dekat saja. Selain itu belum diketahui tingkat kemenangan NPC dari penggunaan metode naïve bayes pada penelitiannya.

Meninjau latar belakang tersebut, akan dilakukan penelitian dengan menerapkan metode naïve bayes untuk aksi penyerangan NPC pada shooter game ber-genre Third Person Shoter (TPS). Metode naïve bayes digunakan untuk pengambilan keputusan penyerangan baik dari jarak dekat maupun dari jarak jauh. Serta akan dilakukan uji coba pada simulasi game untuk mengetahui tingkat kemenangan NPC dibandingkan metode sebelumnya yaitu rulebase.

\section{METODE PENELITIAN}

\subsection{Penentuan Parameter Nä̈ve Bayes}

Dalam perhitungannya metode nä̈ve bayes memerlukan parameter. Parameter yang digunakan pada penelitian ini antara lain jarak, nyawa, jumlah granat, dan jumlah amunisi. Parameter tersebut merupakan atribut pada NPC yang sering mengalami perubahan nilai dalam game sehingga sangat cocok digunakan untuk pengambilan keputusan serangan NPC. Masing-masing parameter yang telah mengalami perubahan akan dibagi menjadi beberapa kriteria.

\begin{tabular}{cc}
\multicolumn{2}{c}{ Tabel 1. Parameter Jarak } \\
jarak & kriteria \\
\hline $12,0<$ jarak $\leq 23,0$ & Jauh \\
$3,0<$ jarak $\leq 12,0$ & Sedang \\
$0,1 \leq$ jarak $\leq 3,0$ & Dekat \\
\multicolumn{3}{c}{ Tabel 2. Parameter Nyawa } \\
\hline nyawa & kriteria \\
\hline $350<$ nyawa $\leq 500$ & Besar \\
$150<$ nyawa $\leq 350$ & Sedang \\
$1 \leq$ nyawa $\leq 150$ & Kecil \\
\hline & \\
Tabel 3. Parameter Jumlah & Granat \\
\hline Jumlah granat & kriteria \\
\hline $10<$ Jumlah granat $\leq 15$ & Banyak \\
$5<$ Jumlah granat $\leq 10$ & Sedang \\
$1 \leq$ Jumlah granat $\leq 5$ & Sedikit \\
Jumlah granat $=0$ & Habis \\
\hline
\end{tabular}


Tabel 4. Parameter Jumlah Amunisi

\begin{tabular}{cc}
\hline Jumlah amunisi & kriteria \\
\hline $30<$ Jumlah amunisi $\leq 50$ & Banyak \\
$15<$ Jumlah amunisi $\leq 30$ & Sedang \\
$1 \leq$ Jumlah amunisi $\leq 15$ & Sedikit \\
Jumlah amunisi $=0$ & Habis \\
\hline
\end{tabular}

\subsection{Perancangan Perilaku NPC}

Perancangan perilaku NPC digambarkan dalam bentuk blok diagram menggunakan metode finite state machine (FSM). Blok diagram digambarkan berdasarkan prinsip kerja sistem mulai dari sistem dijalankan sampai terjadi penyerangan NPC terhadap player.

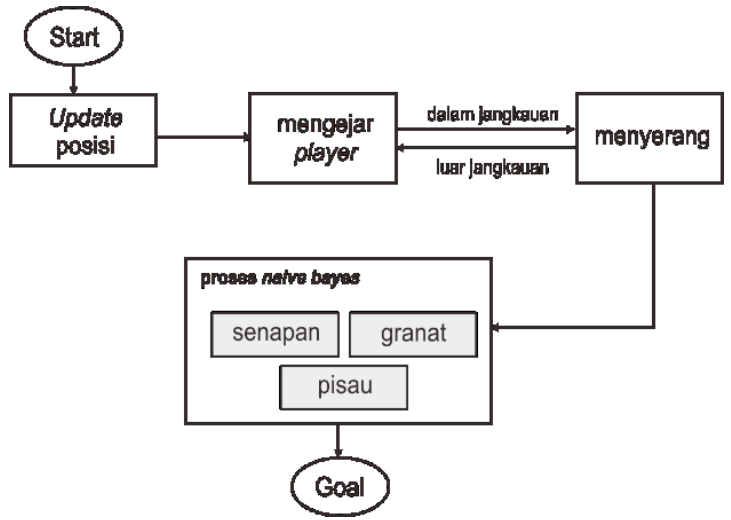

Gambar 1. Blok diagram perilaku NPC

Gambar 1 merupakan desian perilaku NPC. Pada saat sistem dijalankan terjadi perubahan posisi NPC (update posisi) karena terjadi state NPC bergerak mengejar player. NPC akan bertransisi ke state menyerang apabila sudah berada di radius serang atau kondisi dalam jangkauan serang. NPC akan bertransisi kembali ke state mengejar player apabila di luar jangkauan serang.

\subsection{Pembuatan Dataset}

Tahapan awal dalam perhitungan naïve bayes diawali dengan pengambilan data dari kondisi NPC. Data tersebut berisi nilai-nilai parameter. Pengambilan data dilakukan dengan teknik sampling. Setelah pengambilan data kemudian akan diberikan klasifikasi serangan NPC secara manual oleh user yang memiliki user experience dalam game. Data yang telah diklasifikasi seacara manual akan digunakan sebagai dataset. Saleh (2015) menggunakan dataset sebanyak 60 data dalam penelitiannya untuk perhitungan naïve bayes, maka penelitian ini akan digunakan dataset sebanyak 60 . Kemudian dari 60 dataset akan dibagi menjadi 2 subset data yaitu data training dan data testing menggunakan metode simple split. Metode simple split memilih dua per tiga sebagai data training dan satu per tiga sebagai data testing (Talib, Mayadewi, \& Rosely, 2016). Data training dapat dilihat pada Tabel 5 sedangkan data testing dapat dilihat pada Tabel 6. Data training yang telah ditentukan akan diterapkan dalam sistem sebagai data pembelajaran NPC dalam memprediksi serangan yang akan diambil. Sedangkan data testing akan digunakan sebagai data uji ketika NPC dalam kondisi baru.

\begin{tabular}{|c|c|c|c|c|c|}
\hline No & Nyawa & Jarak & $\begin{array}{l}\text { Jumlah } \\
\text { Granat }\end{array}$ & $\begin{array}{l}\text { Jumlah } \\
\text { Amunisi }\end{array}$ & Serangan \\
\hline 1 & Besar & Jauh & Sedikit & Sedang & Tembak \\
\hline 2 & Besar & Sedang & Sedang & Sedang & Granat \\
\hline 3 & Besar & Sedang & Habis & Habis & Pisau \\
\hline 4 & Sedang & Sedang & Sedang & Banyak & Tembak \\
\hline 5 & Kecil & Jauh & Banyak & Sedikit & Granat \\
\hline 6 & Sedang & Dekat & Habis & Banyak & Pisau \\
\hline 7 & Sedang & Sedang & Habis & Sedikit & Tembak \\
\hline 8 & Kecil & Jauh & Banyak & Sedang & Granat \\
\hline 9 & Kecil & Jauh & Habis & Habis & Pisau \\
\hline 10 & Kecil & Sedang & Habis & Sedikit & Tembak \\
\hline 11 & Besar & Jauh & Sedang & Habis & Granat \\
\hline 12 & Besar & Dekat & Sedikit & Sedikit & Pisau \\
\hline 13 & Besar & Sedang & Habis & Sedikit & Tembak \\
\hline 14 & Sedang & Jauh & Banyak & Habis & Granat \\
\hline 15 & Sedang & Dekat & Habis & Sedikit & Pisau \\
\hline 16 & Sedang & Jauh & Habis & Sedang & Tembak \\
\hline 17 & Besar & Jauh & Banyak & Sedang & Tembak \\
\hline 18 & Kecil & Dekat & Sedikit & Sedang & Pisau \\
\hline 19 & Kecil & Dekat & Sedikit & Sedikit & Pisau \\
\hline 20 & Kecil & Sedang & Habis & Sedang & Tembak \\
\hline 21 & Sedang & Sedang & Banyak & Sedang & Granat \\
\hline 22 & Besar & Jauh & Sedikit & Banyak & Tembak \\
\hline 23 & Besar & Sedang & Banyak & Sedang & Granat \\
\hline 24 & Besar & Dekat & Sedang & Habis & Pisau \\
\hline 25 & Kecil & Sedang & Sedikit & Banyak & Tembak \\
\hline 26 & Kecil & Jauh & Sedikit & Sedikit & Granat \\
\hline 27 & Sedang & Dekat & Sedikit & Sedang & Pisau \\
\hline 28 & Kecil & Jauh & Sedang & Banyak & Tembak \\
\hline 29 & Besar & Sedang & Banyak & Sedikit & Granat \\
\hline 30 & Besar & Jauh & Habis & Habis & Pisau \\
\hline 31 & Sedang & Jauh & Sedikit & Banyak & Tembak \\
\hline 32 & Sedang & Sedang & Sedang & Sedikit & Granat \\
\hline 33 & Kecil & Dekat & Habis & Banyak & Pisau \\
\hline 34 & Kecil & Jauh & Banyak & Banyak & Tembak \\
\hline 35 & Besar & Sedang & Sedang & Habis & Granat \\
\hline 36 & Besar & Dekat & Sedikit & Sedang & Pisau \\
\hline 37 & Kecil & Jauh & Habis & Sedikit & Tembak \\
\hline 38 & Kecil & Sedang & Sedang & Banyak & Granat \\
\hline 39 & Sedang & Sedang & Sedang & Sedang & Granat \\
\hline 40 & Besar & Dekat & Banyak & Sedang & Pisau \\
\hline
\end{tabular}

Tabel 6. Data Testing

\begin{tabular}{cccccc}
\hline No & Nyawa & Jarak & $\begin{array}{c}\text { Jumlah } \\
\text { granat }\end{array}$ & $\begin{array}{c}\text { Jumlah } \\
\text { amunisi }\end{array}$ & Serangan \\
\hline 1 & Besar & Jauh & Banyak & Banyak & Tembak \\
2 & Besar & Sedang & Sedikit & Sedikit & Granat \\
3 & Besar & Sedang & Sedikit & Banyak & Tembak \\
4 & Besar & Sedang & Sedang & Sedikit & Granat \\
5 & Besar & Dekat & Sedikit & Banyak & Tembak \\
6 & Besar & Dekat & Banyak & Sedikit & Pisau \\
7 & Sedang & Jauh & Banyak & Banyak & Tembak \\
8 & Sedang & Jauh & Sedikit & Sedang & Tembak \\
9 & Sedang & Jauh & Sedikit & Habis & Granat \\
10 & Sedang & Sedang & Banyak & Sedikit & Granat \\
11 & Sedang & Dekat & Banyak & Banyak & Pisau \\
12 & Sedang & Dekat & Sedang & Sedikit & Pisau \\
13 & Sedang & Dekat & Sedikit & Habis & Pisau \\
14 & Kecil & Jauh & Sedikit & Sedang & Tembak \\
15 & Kecil & Sedang & Banyak & Banyak & Tembak \\
16 & Kecil & Sedang & Sedang & Sedang & Granat \\
17 & Kecil & Dekat & Banyak & Banyak & Tembak \\
18 & Kecil & Dekat & Sedang & Banyak & Pisau \\
19 & Kecil & Dekat & Sedang & Sedikit & Pisau \\
20 & Besar & Jauh & Banyak & Banyak & Pisau \\
\hline & & & & &
\end{tabular}




\subsection{Implementasi Nä̈ve Bayes pada NPC}

Ketika menyerang maka terjadi perubahan kondisi baik jarak pemain dengan NPC, nyawa, jumlah granat, dan jumlah amunisi yang dimiliki NPC. Perubahan tersebut dijadikan parameter sebagai masukan perhitungan proses nä̈ve bayes.

$$
\mathrm{P}(\mathrm{C} \mid \mathrm{X})=\frac{\mathrm{P}(\mathrm{X} \mid \mathrm{C}) \cdot \mathrm{P}(\mathrm{C})}{\mathrm{P}(\mathrm{X})}
$$

Persamaan 1 merupakan persamaan naïve bayes. $\mathrm{P}(\mathrm{C} \mid \mathrm{X})$ merupakan probabilitas posterior yaitu nilai yang akn dijadikan keputusan serangan NPC. $\mathrm{P}(\mathrm{C})$ merupakan probabilitas prior, $\mathrm{P}(\mathrm{X} \mid \mathrm{C})$ merupakan probabilitas likehood yaitu peluang kemunculan nilai parameter X pada kelas tertentu C. sedangkan $\mathrm{P}(\mathrm{X})$ merupakan evidence yaitu peluang munculnya parameter $\mathrm{X}$ dari seluruh pengamatan. Langkah kerja proses naïve bayes secara detail dapat dilihat dalam bentuk flowchart pada Gambar 2 .

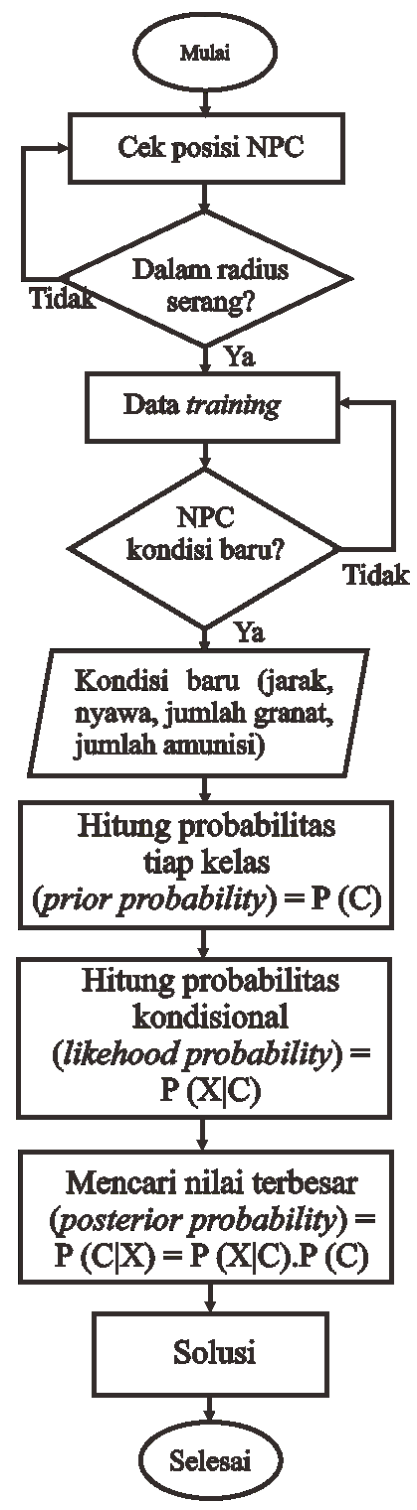

Gambar 2. Proses naïve bayes pada NPC
Pada Gambar 2 dapat dilihat bahwa sistem akan mengecek posisi NPC apakah berada pada radius serang atau diluar radius serang. Ketika NPC berada pada radius serang maka NPC akan menyerang player sesuai kondisi pada saat itu.

\section{HASIL DAN PEMBAHASAN}

Pada tahap hasil dan analisis adan dipaparkan hasil simulasi game, hasil pengujian akurasi, dan hasil pengujian tingkat kemenangan NPC.

\subsection{Hasil Simulasi Game}

Setelah dilakukan perancangan kemudian akan diimplementasikan kedalam tools game engine Unity3D. Tampilan simulasi game dapat dilihat pada Gambar 3 sampai 4.

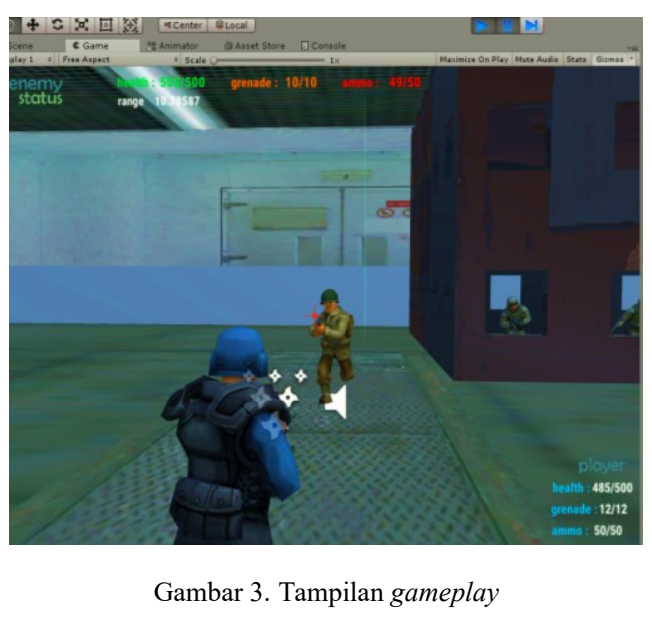

Gambar 3 merupakan tampilan awal saat game dijalankan. Terlihat bahwa hanya ada 1 pemain dan 1 NPC pada simulasi game ini. Selanjutnya gambar 4 merupakan tampilan penerapan data training pada tools game. Data training disimpan dalam bentuk file yang berekstensi .txt sebagai database dalam proses perhitungan nä̈ve bayes.

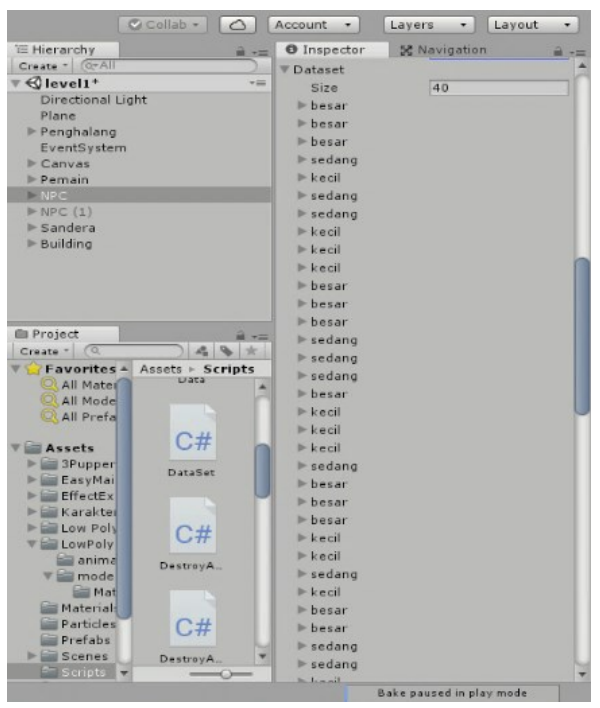

Gambar 4. Implenentasi data training 


\subsection{Hasil Pengujian Akurasi}

Pengujian akurasi berfungsi untuk mengetahui ketepatan NPC dalam memprediksi serangan dengan benar terhadap keseluruhan data. Pengujian akurasi diperoleh dengan melakukan percobaan yaitu memainkan game dimana NPC sudah diberikan data training. Kemudian kondisi NPC akan dimanipulasi agar mendapat data baru sesuai data testing dan mengamati respon serangan yang dilakukan NPC. Berdasarkan pengujian yang telah dilakukan didapatkan hasil seperti pada Tabel 7 .

Tabel 7. Hasil pengujian akurasi

\begin{tabular}{|c|c|c|c|c|c|c|c|}
\hline No & Nxyawa & Jarak & Jumlah granat & Jumlah amunisi & $\begin{array}{c}\text { Klasifikasi } \\
\text { manual }\end{array}$ & $\begin{array}{c}\text { Klasifikasi } \\
\text { sistem }\end{array}$ & Kesimpulan \\
\hline 1 & Besar & Jauh & Banyak & Banyak & Tembak & Tembak & Sesuai \\
\hline 2 & Besar & Sedang & Sedikit & Sedikit & Granat & Tembak & Tidak sesuai \\
\hline 3 & Besar & Sedang & Sedikit & Banyak & Tembak & Tembak & Sesuai \\
\hline 4 & Besar & Sedang & Sedang & Sedikit & Granat & Granat & Sesuai \\
\hline 5 & Besar & Dekat & Sedikit & Banyak & Tembak & Pisau & Tidak sesuai \\
\hline 6 & Besar & Dekat & Banyak & Sedikit & Pisau & Pisau & Sesuai \\
\hline 7 & Sedang & Jauh & Banyak & Banyak & Tembak & Tembak & Sesuai \\
\hline 8 & Sedang & Jauh & Sedikit & Sedang & Tembak & Tembak & Sesuai \\
\hline 9 & Sedang & Jauh & Sedikit & Habis & Granat & Pisau & Tidak sesuai \\
\hline 10 & Sedang & Sedang & Banyak & Sedikit & Granat & Granat & Sesuai \\
\hline 11 & Sedang & Dekat & Banyak & Banyak & Pisau & Pisau & Sesuai \\
\hline 12 & Sedang & Dekat & Sedang & Sedikit & Pisau & Pisau & Sesuai \\
\hline 13 & Sedang & Dekat & Sedikit & Habis & Pisau & Pisau & Sesuai \\
\hline 14 & Kecil & Jauh & Sedikit & Sedang & Tembak & Tembak & Sesuai \\
\hline 15 & Kecil & Sedang & Banyak & Banyak & Tembak & Tembak & Sesuai \\
\hline 16 & Kecil & Sedang & Sedang & Sedang & Granat & Granat & Sesuai \\
\hline 17 & Kecil & Dekat & Banyak & Banyak & Tembak & Pisau & Tidak sesuai \\
\hline 18 & Kecil & Dekat & Sedang & Banyak & Pisau & Pisau & Sesuai \\
\hline 19 & Kecil & Dekat & Sedang & Sedikit & Pisau & Pisau & Sesuai \\
\hline 20 & Kecil & Dekat & Sedikit & Habis & Pisau & Pisau & Sesuai \\
\hline
\end{tabular}

Hasil pengujian akurasi pada Tabel 7 kemudian akan dianalisis menggunakan metode confussion matrix. Tujuannya adalah untuk melihat performa metode naïve bayes pada pengambilan keputusan serangan NPC. Pada penelitian ini akan digunakan model confussion matrix $3 \times 3$ (multiclass) karena klasifikasi serangan ada 3 kelas yaitu serangan tembak, serangan granat, dan serangan pisau. Model confussion matrix $3 \times 3$ dapat dilihat pada Tabel 8 .

\begin{tabular}{ccccc} 
Tabel 8. Confussion matrix (Iskandar \& Suprapto, 2015) \\
\hline \multicolumn{5}{c}{ Predicted class } \\
\hline & & Class A & Class B & Class C \\
$\frac{5}{5}$ & Class A & AA & AB & AC \\
$\vdots$ & Class B & BA & BB & BC \\
\hline & Class C & CA & CB & CC \\
\hline
\end{tabular}

Keterangan:

Class $\mathrm{A}=$ Kelas dengan nama $\mathrm{A}$

Class $\mathrm{B}=$ Kelas dengan nama $\mathrm{B}$

Class $\mathrm{C}=$ Kelas dengan nama $\mathrm{C}$

$\mathrm{AA}=$ Jumlah data dengan nilai sebenarnya A dan diprediksi tepat sebagai kelas A

$\mathrm{AB}=$ Jumlah data dengan nilai sebenarnya $\mathrm{A}$ dan diprediksi sebagai kelas B

$\mathrm{AC}=$ Jumlah data dengan nilai sebenarnya A dan diprediksi sebagai kelas $\mathrm{C}$
$\mathrm{BA}=$ Jumlah data dengan nilai sebenarnya $\mathrm{B}$ dan diprediksi sebagai kelas A

$\mathrm{BB}=$ Jumlah data dengan nilai sebenarnya $\mathrm{B}$ dan diprediksi tepat sebagai kelas $\mathrm{B}$

$\mathrm{BC}=$ Jumlah data dengan nilai sebenarnya $\mathrm{B}$ dan diprediksi sebagai kelas $\mathrm{C}$

$\mathrm{CA}=$ Jumlah data dengan nilai sebenarnya $\mathrm{C}$ dan diprediksi sebagai kelas A

$\mathrm{CB}=$ Jumlah data dengan nilai sebenarnya $\mathrm{C}$ dan diprediksi sebagai kelas B

$\mathrm{CC}=$ Jumlah data dengan nilai sebenarnya $\mathrm{C}$ dan diprediksi tepat sebagai kelas $\mathrm{C}$

Adapun hasil analisis menggunakan confussion matrix ditunjukkan pada Tabel 9 .

Tabel 9. Nilai confussion matrix

\begin{tabular}{ccccc}
\hline \multicolumn{5}{c}{ Klasifikasi sistem (predicted class) } \\
\hline & $\begin{array}{c}\text { Class A } \\
\text { (Tembak) }\end{array}$ & $\begin{array}{c}\text { Class } \mathrm{B} \\
\text { (Granat) }\end{array}$ & $\begin{array}{c}\text { Class } \mathrm{C} \\
\text { (Pisau) }\end{array}$ \\
& $\begin{array}{c}\text { Class A } \\
\text { (Tembak) }\end{array}$ & 6 & 0 & 2 \\
& $\begin{array}{c}\text { Class B } \\
\text { (Granat) }\end{array}$ & 1 & 3 & 1 \\
\hline
\end{tabular}

Berdasarkan tabel 9 hasil confussion matrix didapatkan bahwa 6 data pada kelas serangan tembak diprediksi tepat sebagai kelas serangan tembak dan sebanyak 3 data pada kelas serangan granat diprediksi tepat sebagai serangan granat serta sebanyak 7 data serangan pisau diprediksi tepat 
sebagai serangan pisau. Selain itu terdapat 2 data klasifikasi manual pada serangan granat yang diprediksi tidak tepat sebagai serangan granat yaitu 1 data diprediksi sebagai serangan tembak dan 1 data diprediksi sebagai serangan pisau. Terdapat juga 2 data pada klasifikasi manual serangan tembak yang diprediksi tidak tepat sebagai kelas serangan tembak yaitu 2 data diprediksi sebagai sebagai serangan pisau dan 0 data diprediksi sebagai serangan granat. Sedangkan semua data pada klasifikasi manual serangan pisau diprediksi tepat sebagai serangan pisau. Dari hasil tersebut dapat dihitung akurasi sesuai persamaan 2 .

Akurasi

$$
=\frac{A A+B B+C C}{A A+A B+A C+B A+B B+B C+C A+C B+C C} \times 100 \%
$$

$$
\begin{aligned}
\text { Akurasi } & =\frac{6+3+7}{6+0+2+1+3+1+0+0+7} \times 100 \% \\
& =\frac{16}{20} \times 100 \% \\
& =80 \%
\end{aligned}
$$

Berdasarkan perhitungan akurasi diperoleh nilai akurasi sebesar $80 \%$. Nilai akurasi ini sama seperti nilai akurasi pada penelitian Asmiatun \& Hendrawan (2016) namun pada penelitian tersebut belum diketahui tingkat kemenangan NPC.

\subsection{Hasil Pengujian Tingkat Kemenangan NPC}

Pengujian tingkat kemenangan NPC dilakukan dengan memainkan game oleh pemain (pakar game). Selama pengujian akan dicatat hasil percobaan (menang atau kalah) dan sisa nyawa pemain. Uji coba dilakukan oleh 5 orang gamers, masing-masing melakukan uji coba sebanyak 10 kali secara bergantian pada tiap metode. Sehingga didapatkan sebanyak 50 kali percobaan untuk setiap metode. Jumlah percobaan ini sudah cukup untuk melihat perbedaan yang signifikan pada tingkat kemenangan NPC dari masing-masing metode uji coba.

Adapun yang akan dijadikan rulebase sebagai AI pada NPC adalah data training pada metode naïve bayes. Sehingga terdapat 40 rulebase. Contoh rulebase yang digunakan:

1. If (nyawa $=$ besar and jarak $=$ jauh and jumlah granat $=$ sedikit and jumlah amunisi $=$ sedang) then serangan tembak

2. If (nyawa $=$ besar and jarak = sedang and jumlah granat $=$ sedang and jumlah amunisi $=$ sedang) then serangan granat

3. If (nyawa $=$ besar and jarak = sedang and jumlah granat $=$ habis and jumlah amunisi $=$ habis) then serangan pisau

4. If (nyawa = sedang and jarak = sedang and jumlah granat $=$ sedang and jumlah amunisi $=$ banyak) then serangan tembak
5. If (nyawa = besar and jarak = sedang and jumlah granat $=$ habis and jumlah amunisi $=$ habis) then serangan pisau

6. If (nyawa $=$ sedang and jarak $=$ dekat and jumlah granat $=$ habis and jumlah amunisi $=$ banyak) then serangan pisau

7. If (nyawa $=$ sedang and jarak $=$ sedang and jumlah granat $=$ habis and jumlah amunisi $=$ sedikit) then serangan tembak

8. If (nyawa $=$ kecil and jarak $=$ jauh and jumlah granat = banyak and jumlah amunisi $=$ sedang) then serangan granat

9. If (nyawa $=$ kecil and jarak $=$ jauh and jumlah granat $=$ habis and jumlah amunisi $=$ habis) then serangan pisau

10. If (nyawa $=$ kecil and jarak $=$ sedang and jumlah granat $=$ habis and jumlah amunisi $=$ sedikit) then serangan tembak

Berdasarkan hasil uji coba antara pemain dengan kedua metode, diperoleh jumlah kemenangan NPC sebanyak 30 kali dan jumlah kekalahan sebanyak 20 kali pada metode naïve bayes sedangkan rulebase NPC mendapat kemenangan sebanyak 8 kali serta 42 kali kalah dari 50 kali percobaan. Sehingga tingkat kemenangan NPC dapat dihitung sesuai persamaan 3 (Abdi, et al., 2017).

$\%$ Kemenangan $=\frac{\text { Jumlah kemenangan NPC }}{\text { Jumlah semua pertandingan }} \times 100 \%$

NPC Naïve bayes $=\frac{30}{50} \times 100 \%=60 \%$

NPC Rulebase $=\frac{8}{50} \times 100 \%=16 \%$

Tabel 10. Hasil uji coba pemain

\begin{tabular}{ccccc}
\hline metode & $\begin{array}{c}\text { Jumlah } \\
\text { NPC } \\
\text { menang }\end{array}$ & $\begin{array}{c}\text { Jumlah } \\
\text { NPC } \\
\text { kalah }\end{array}$ & $\begin{array}{c}\text { Tingkat } \\
\text { kemenangan } \\
\text { NPC }\end{array}$ & $\begin{array}{c}\text { Jumlah } \\
\text { sisa } \\
\text { nyawa } \\
\text { pemain }\end{array}$ \\
\hline $\begin{array}{c}\text { Nä̈ve } \\
\text { bayes }\end{array}$ & 30 & 20 & $60 \%$ & 38,9 \\
Rulebase & 8 & 42 & $16 \%$ & 89,12 \\
\hline
\end{tabular}

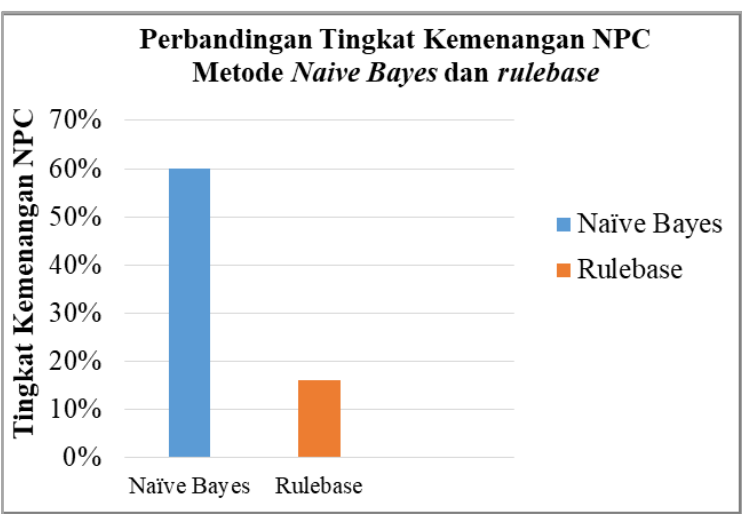

Gambar 5. Perbandingan tingkat kemenangan NPC 


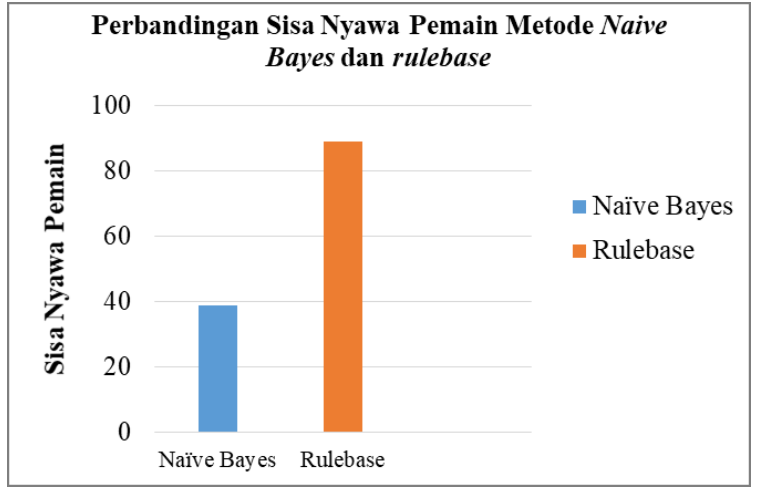

Gambar 6. Perbandingan sisa nyawa pemain

Berdasarkan pengujian tingkat kemenangan NPC dengan menggunakan metode naïve bayes didapatkan tingkat kemenangan NPC yang lebih besar jika dibandingkan metode rulebase. Gambar 5 menunjukkan bahwa tingkat kemenangan NPC pada metode naïve bayes memiliki tingkat persentase lebih besar yaitu sebesar $60 \%$ dibandingkan metode rulebase. Hal ini menunjukkan bahwa NPC pada metode naïve bayes memiliki jumlah kemenangan yang lebih banyak dari setiap percobaan. Oleh karena itu dapat dikatakan bahwa metode naïve bayes memberikan tingkat kemenangan pada NPC yang lebih tinggi dibandingkan metode rulebase sebagai kecerdasan buatan pada NPC. Selain menghitung persentase tingkat kemenangan NPC, dilakukan pula menghitung jumlah sisa nyawa dari pemain. Tujuannya adalah mengetahui seberapa agresif NPC dalam melakukan serangan ke pemain. Apabila diakhir pertandingan sisa nyawa pemain sedikit maka NPC lebih agresif dalam melakukan serangan.

Hasil uji coba diperoleh hasil bahwa penerapan metode naïve bayes membuat NPC lebih agresif dalam melakukan serangan. Hal ini terbukti dari rata-rata sisa nyawa pemain jika melawan metode naïve bayes sisa nyawa pemain lebih sedikit dibandingkan melawan rulebase. Sisa nyawa pemain pada metode naïve bayes rata-rata sisa 38,9 sedangkan pada rulebase rata-rata sisa 89,12 seperti yang ditunjukkan pada Gambar 6. Pada metode naïve bayes NPC dapat melakukan serangan secara otonom jika terjadi kondisi baru sehingga NPC lebih agresif dalam menyerang pemain, sedangkan penggunaan rulebase, NPC bisa menyerang apabila telah memenuhi rulebase yang dibuat. Sehingga NPC belum adaptif jika terjadi kondisi baru.

\section{KESIMPULAN}

Berdasarkan hasil penelitian dan implementasi metode naïve bayes pada game shooter maka diperoleh simpulan bahwa:

1. Implementasi metode nä̈ve bayes berhasil diterapkan sebagai kecerdasan buatan untuk strategi penyerangan NPC dalam pengambilan keputusan serangan dengan akurasi sebesar $80 \%$.
2. Metode nä̈ve bayes memberikan tingkat kemenangan NPC yang lebih baik dibanding menggunakan rulebase. Metode naïve bayes mendapat tingkat kemenangan sebesar $60 \%$, sedangkan rulebase sebesar $16 \%$.

Pada penelitian ini dibatasi bahwa metode naïve bayes hanya digunakan untuk memilih keputusan serangan yang diambil NPC. Sehingga perlu dilakukan pengembangan lebih lanjut seperti memberikan keputusan perilaku NPC untuk bersembunyi, atau dapat menggunakan metode lain untuk menambah perilaku NPC tersebut.

\section{DAFTAR PUSTAKA}

ABDI, M., HERUMURTI, D., \& KUSWARDAYAN, I. (2017). Analisis Perbandingan Kecerdasan Buatan pada Computer Player dalam Mengambil Keputusan pada Game Battle RPG. JUTI: Jurnal Ilmiah Teknologi Informasi, 15(2), 226-237.

https://doi.org/10.12962/j24068535.v15i2.a67 1 .

GATA, W., BASRI, H., HIDAYAT, R., PATRAS, Y. E., BAHARUDDIN, B., FATMASARI, R., TOHARI, S., \& WARDHANI, N. K. (2019). Algorithm Implementations Naïve Bayes, Random Forest. C4.5 on Online Gaming for Learning Achievement Predictions. International Conference on Research of Educational Administration and Management (ICREAM), 258(Icream 2018), 1-9. https://doi.org/10.2991/icream-18.2019.1

ASMIATUN, S., \& HENDRAWAN, A. (2016). Implementasi Klasifikasi Bayesian Untuk Strategi Menyerang Jarak Dekat Pada Npc (Non Player Character)Menggunakan Unity 3D. Jurnal Transformatika, 13(2), 42. https://doi.org/10.26623/transformatika.v13i2. 139

ASMIATUN, S., HERMAWAN, L., \& DARYATNI, T. (2013). Strategi Menyerang Jarak Dekat Menggunakan Klasifikasi Bayesian Pada NPC (Non Player Character). Semantik, 3(1), 351-357.

F. OSISANWO., J.E.T, AKINSOLA., O, AWODELE., J. O, HIMNIKAIYE., O, O., \& J, A. (2017). Supervised Machine Learning Algorithms: Classification and Comparison. International Journal of Computer Trends and Technology, 48(3), 128-138. https://doi.org/10.14445/22312803/ijcttv48p126

FROSI, F. O., \& CRISTINA, I. (2018). Building Bots for Shooter Games based on the Bartle' s Player Types and Finite State Machines: A Battling Behaviour Analysis. 631-634. 
ISKANDAR, D., \& SUPRAPTO, Y. K. (2015). Perbandingan Akurasi Klasifikasi Tingkat Kemiskinan Antara Algoritma C 4.5 dan Naive Bayes. Jurnal Ilmiah NERO, 2(1), 3743.

KAVIANI, P., \& DHOTRE, S. (2017). Short Survey on Naive Bayes Algorithm. International Jurnal of Advance Engineering and Research Development, 4(11).

LIAROKAPIS, F., DEBATTISTA, K., VOURVOPOULOS, A., \& ENE, A. (2014). Comparing Interaction Techniques for Serious Games through Brain-Computer Interfaces : A User Perception Evaluation Study. Entertainment Computing https://doi.org/10.1016/j.entcom.2014.10.004

PUTERA, M. I. A., \& MURTI, D. H. (2018). Peningkatan Kecerdasan Computer Player Pada Game Pertarungan Berbasis K-Nearest Neighbor Berbobot. JUTI: Jurnal Ilmiah Teknologi Informasi, 16(1), 90. https://doi.org/10.12962/j24068535.v16i1.a71 0

ROSTIANINGSIH, S., GREGORIUS, S. B., \& WIJAYA, H. K. (2013). Game Simulasi Finite State Machine Untuk Pertanian Dan Peternakan. Jurnal DKV Adiwarna, 5, 2-7.

SAFRIZAL, \& SETIAWAN, D. R. (2019). Penerapan Algoritma Minimax Dengan Optimasi Memory Enhcanced Test Driver With Value F Pada Game Catur. Ilmiah Fakultas Teknik, 1, 1-476. https://doi.org/10.1017/CBO9781107415324.0 04

SALEH, A. (2015). Implementasi Metode Klasifikasi Nä̈ve Bayes Dalam Memprediksi Besarnya Penggunaan Listrik Rumah Tangga. 2(3),207-217. https://doi.org/10.24076/citec.2015v2i3.49

SANJAYA, S. W., AKBAR, M. A., \& AFIRIANTO, T. (2019). Penerapan Naïve Bayes untuk NPC Braking Decision pada Racing Game. Jurnal Pengembangan Teknologi Informasi Dan Ilmu Komputer (JPTIIK) Universitas Brawijaya, 3(4), 3252 3257.

TALIB, F. Z., MAYADEWI, R. P., \& ROESLY, E. (2016). Aplikasi Prediksi Peminatam SMAN 8 Bandung Menggunakan Metode Klasifikasi Dengan Algoritma ID3. 2(3), 1053-1061.

WANG, D., \& TAN, A. H. (2015). Creating Autonomous Adaptive Agents in a Real-Time First-Person Shooter Computer Game. IEEE Transactions on Computational Intelligence and AI in Games, 7(2), 123-138. https://doi.org/10.1109/TCIAIG.2014.2336702
WICAKSONO, A., HARIADI, M., \& N, S. MARDI. S. (2013). Strategi Menyerang Npc Game Fps Menggunakan Fuzzy Finite State Machine. 25-30.

YUNANTA, D. P. (2017). Game Rescue Idol Dengan Menggunakan Metode Finite State Machine (Fsm ). 1(2), 96-103. 